\title{
Enkinaesthesia: Proto-moral value in action-enquiry and interaction
}

\author{
Susan A. J. Stuart $^{1}$ (D)
}

Published online: 7 June 2017

(C) The Author(s) 2017. This article is an open access publication

\begin{abstract}
It is now generally accepted that human beings are naturally, possibly even essentially, intersubjective. This chapter offers a robust defence of an enhanced and extended intersubjectivity, criticising the paucity of individuating notions of agency and emphasising the community and reciprocity of our affective co-existence with other living organisms and things. I refer to this modified intersubjectivity, which most closely expresses the implicit intricacy of our pre-reflective neuro-muscular experiential entanglement, as 'enkinaesthesia'. The community and reciprocity of this entanglement is characterised as dialogical, and in this dialogue, as part of our anticipatory preparedness, we have a capacity for intentional transgression, feeling our way with our world but, more particularly, co-feeling our way with the mind and intentions of the other. Thus we are, not so much 'mind'-reading, as 'mind'-feeling, and it is through this enkinaesthetic 'mind'-feeling dialogue that values-realising activity originates and we uncover the deep roots of morality.
\end{abstract}

Keywords Proto-moral value · Agency · Anticipation · Still-face · Enkinaesthesia · Intertwining

\section{Introduction}

In this chapter I will attempt to convey a fairly straightforward idea, and that idea is this: that meaning and value are implicit in an organism's affective agency. The agency with which we are concerned is human, both pre- and post-natal, though there is little reason to think that what holds for human agents in this discussion should not also hold for other animal agents, with the exception of the shift to a conceptualised ethical

Susan A. J. Stuart

Susan.Stuart@glasgow.ac.uk

1 School of Humanities, University of Glasgow, 11 University Gardens, Glasgow, UK 
discourse; this conceptual shift, with its associated moral concepts and analysis, is not the subject of this paper.

The broad background for the idea, that meaning and value are implicit in an organism's affective agency, arises from a number of sources, these include, but are not limited to, Reid's theory of direct perception (1764; 1788 \& 1983), Gibson's ecological approach to perception (1979), and the approach to perception as a kind of doing or action, which is favoured by, amongst others, O'Regan and Noë (2001) and Noë (2004).

Reid wrote in defence of a common sense view of perception, arguing that our perception of objects is both immediate and non-inferential. As a perceptual theory it has been described as 'naïve', but the very fact that it does not over-theorise when overtheorising is in unnecessary ${ }^{1}$ is one of its considerable merits. So, when I perceive the cat, I perceive the cat directly as a real object, and not indirectly as an idea of the cat. ${ }^{2}$

In addition Reid discusses the special experiential character of each of our senses, with our sensations of touch, for example, being quite different from our sensations of sight or smell, and smell being quite different in its sensuous content from our auditory sense. Although our sensory experiences have different channels, they do not operate in isolation from each other; in fact we know our senses act severally in terms of both their cross-integration and their plasticity (Shimoko and Shams 2001). Given all of this, perception is, for Reid, as it is also for Noë and O'Regan, an explorative sensuous activity involving the whole living organism-environment. Such embodied exploration, such dynamically-coupled agency, comes already clothed in 'aboutness', which is to say that sensuous perceptual enquiry is, by its very nature, intentionally-saturated (Steinbock 1999). We exist in our world and all our somatosensory perceptual enquiry is about our world, and we are as much part of that world as anything else of which we can have empirical sensation.

From a pragmatic perspective the experiential worlds which we, in our agency, enact from moment to moment, are those which have meaning for us, and, I contend, they have meaning for us through our direct perception of value. My lead in this claim is Gibson's 'radical hypothesis ...that the 'values' and 'meanings' of things in the environment can be directly perceived" (Gibson 1979, p.127). ${ }^{3}$ Gibson's claim is fleshed out in terms of environmental affordances: "what it offers the animal, what it provides or furnishes, either for good or ill" (ibid.); they are "relative to the animal. ...(and) ...unique for that animal". Sensuous perception of affordances is direct, immediate and non-inferential, a pragmatic grasp, a sensuous understanding. In our agency our action and understanding are united in our direct perceptual experience of our world and "I make action the basis of all value" (Bennett 2010, p.1). Thus "[E]very

\footnotetext{
1 "It is genius, and not the want of it, that adulterates philosophy, and fills it with error and false theory." (Reid 1764, p.8)

${ }^{2}$ The representational (or causal) theory of mind is best exemplified by John Locke's theory of perception with its experience of secondary quality sensations, its inference to the existence of primary qualities which inhere in the object, and its proposal that we form, from our sensations, simple and complex ideas about the 'perceived' object: "Whatsoever the mind perceives in itself, or is the immediate object of perception, thought, or understanding, that I call idea" (Locke 1844, p.93). Locke still wants to maintain the real existence of mindindependent objects, but it's considerably more difficult for him, than for Reid, when they, the objects, are known only mediately and inferentially.

${ }^{3}$ There are perspectives, mainly cognitivist and representationalist, for example, Putnam (1991), Carruthers (2005), Fodor (2008), and Goldman and De Vignemont (2009), for which this hypothesis remains 'radical', but there is no possibility of replying to these perspectives in this current chapter.
} 
action ... that consists of perception and operation imprints its meaning on the meaningless object and thereby makes it into a subject-related meaning-carrier in the respective Umwelt (subjective universe)" (von Uexküll 1982/1940, 31), for "it is not (conceptual) laws, or the rules appended to them, ...that ultimately guide the behavior of organisms and the acts of agents, but values" (Hodges \& Baron, p.266).

And, so, I will argue that meaning and value are implicit in an organism's affective agency, that they are implicit in the pre-natal infant's perceptual action enquiry, and that agency is meaning making through direct perception of value. So, let's get under way proper by examining the nature of agential activity, paying special attention to its intersubjectivity and its affectivity.

Human beings act in the world as conscious, socially and culturally embedded, experiencing agents, who are rich in their unique experiential histories, and rich in their greatly distributed, complex array of felt affective relations and interrelations with other agents and things. Within this discussion I will present a couple of the practical implications of this claim: firstly, that all of our activity is co-constituting activity, which is to say that no action is non-situated, and no action exists that is not already in affective relations and interrelations with other agents and things; and secondly, that all affective action-enquiry yields further affective action-enquiry, not as individuated actions but as part of a continuous interactive interrelated process. Furthermore, within this process all affective action-enquiry realises values for the agent; these values affect the agent and their world feeding forward into and influencing all subsequent actionenquiry. I will argue that affective action-enquiry is characterised by a felt anticipatory dynamics which enables the agent to progress feelingly rather than by means of some cognitive interpretation of another action or anticipated action. In this way we are, through our situated and affective intersubjective entanglement, able to anticipate the other's intentional trajectory, and adapt appropriately, that is, in a congruous or consonant manner. This is not to claim that all adaptation is consonant or attuned, sometimes it can be discordant or fragmentary. I will argue that these affective enquiries and influences, with their consonance and dissonance, are the protomoral agential activity which provides the deep roots of our cultural moral discourse.

There is one thing to add about terminology before we proceed. When we have established the groundwork, I will introduce the term 'enkinaesthesia' to refer to the community and reciprocity of affective co-engagement described very briefly above. The word has come about because it expresses the experiential entanglement of our sensori-kinaesthetic action-enquiry, that is, the reciprocally affective neuro-muscular dynamical flows and muscle tensions that are felt and enfolded between coparticipating agents and objects; thus, it will be presented as 'en'-'kinaesthesia'. It is not another word for empathy; it is something without which the experience of empathy could not occur. Therefore, I will argue that the capacity for enkinaesthetic dialogue is an a priori nomological condition for agency and the generation of the felt anticipatory dynamics within and between agents, and that it is essential if moral discourse is to have the fertile - protomoral - ground from which it might spring.

And, finally, the level of description with which we will be primarily concerned is specifiable in affective sensori-kinaesthetic terms, though nothing that I say here rules out other levels of description, for example, of human agential experience as specifiable in cognitive and conceptual terms, characterised by, for example, propositional attitudes, or even specific neural activity; but this is not our concern in this chapter. 


\section{Agential activity}

All our actions are part of our continuously changing experiential horizon, whether stretching a hand out tentatively to feel the texture and resistance of an object, or glancing behind us to check the movement we detected from the corner of our eye, or sniffing the air to locate the direction from which the smell is wafting, or even just stepping out onto the ground before us; and in each action we ask tacit, pre-reflective, pre-conceptual, non-propositional questions about our world, and how it continues to be for us (Cotterill $1995 \&$ 1998). ${ }^{4}$ Thus when I step out I am asking if the ground will continue to resist my downward tread, will the air pressure impede my progress, will I be able to walk noiselessly or is there is something which will snap as I step forward, and so on. It is a plenisentient enquiry, using the agent's senses synaesthetically, not one by one or individually; so, as we reach, glance, sniff or step we simultaneously experience our muscle tensions and tones in the form of our kinaesthetic sense, and this kinaesthetic sense is essential for the effective operation of our tactual, visual and proprioceptive senses, along with the activity of our vestibular system, in order to keep us orientated and maintain our sense of an uninterrupted perspective. ${ }^{5}$

It is through the habitual action of stepping, glancing, reaching, touching, and so on, that kinaesthetic memories and melodies are created, and a kinaesthetic imagination, with its felt anticipatory dynamics, is developed (Stuart 2007; Wood and Stuart 2009). ${ }^{6}$ This felt anticipatory dynamics is crucial for two things; the first is the formation of a sense of familiarity with our world, and the second is the formation of expectations for how the world will continue to be and become for us. So, every action is directed, every action is anticipatory, and every action takes place within a horizon of action possibilities for the agent. In this way, every action embodies and enacts the implicit non-propositional questions "how is my world now?", "how is it ...becoming?", and so on. The responses to these questions affect the agent and bring about fresh horizons of action possibilities in a perpetual plenisentient, non-conceptual questioning in action and questioning in responding. Thus, our living experience is characterised by the ceaseless nature of our agential action-enquiry.

Of course, when we speak about agential activity and worlds, the worlds also include other living agents, and not merely the ground on which we walk or the objects for which we can reach and touch. We are primarily inter-agential, gaining a sense of our own felt agency - what Henry (1963) describes as the 'givenness' of our experience - only because we exist within an affective environment of other moving and feeling

\footnotetext{
${ }^{4}$ Gibson says something very similar to this, though only for the visual sense, when he argues that "The visual system hunts for comprehension and clarity. ...Exploring and optimizing seem to be the functions of the system." (Gibson 1979, p.219).

5 There are some very well-documented cases of neuronopathy - damage or disease affecting the peripheral nervous system and potentially leading to proprioceptive and tactual loss; see, for example, Jeannerod et al. 1984; Sacks 1985, particularly Chapter 3 "The Disembodied Lady"; Forget and Lamarre 1987; and Cole 1991/Cole 1995. These cases demonstrate the necessity of plenisentience, synaesthesia, and spontaneous sensory responses to our non-propositional somatosensory questions, if we are to have the experience of our own diachronic agency.

${ }^{6}$ Kinaesthetic memories are formed through sensorimotor trial and error, for example, building up a kinaesthetic memory for holding a pencil, as opposed to wielding a crayon; and, kinaesthetic melodies are the result of the habituation of kinaesthetic memories. So, instead of just holding my pencil and managing to spell my name in an awkward ham-fisted manner, I practise and habituate writing my signature, thus "with the development of motor skills the individual impulses are synthesized ... into integral kinaesthetic structures or kinetic melodies" (Luria 1973, p.176).
} 
agents. We might characterise this inter-agentiality as occurring within a community and reciprocity of living being, ${ }^{7}$ where each action engenders affect and that affect engenders action, not just within ourselves but within all life. Under this interpretation we experience our world feelingly before we experience it cognitively, and yet, as human beings we are also intersubjective, subjects of our own experience who become aware of ourselves as subjects only because there are first others who interact with us as living, conscious subjects. ${ }^{8}$ Thompson sums this up nicely saying that "Individual human consciousness is formed in the dynamic interrelation of self and other, and therefore is inherently intersubjective." (Thompson 2001, p.1).

Let's examine the nature of this inherent interrelation of self and other, with an emphasis on its being feelingly situated within the affective interrelation of all life. ${ }^{9} \mathrm{We}$ will begin by exploring the nature of the boundaries we perceive between self and other, and, most importantly, how these boundaries are also our means for reciprocal affective communication; and then we will present some practical cases of prenatal fetal activity, regarding the interrelation of singletons and twins with their environment; this should provide ample support for Thompson's claim that we are inherently intersubjective.

\section{The interrelation of self and other}

The fundamental claim in this section is that the boundaries which seem to encase or surround us, and which can, at first, appear rigid and individuating, are in fact, mutable and yielding. They are mutable and yielding because they are organic, living and breathing pseudo-boundaries. They include the protean extent and dimensions of our body, and the social, personal, and cultural pseudo-boundaries we trespass routinely in our day-to-day intersubjective living together. They are pseudo-boundaries because, although they appear to separate us from our worlds, they operate in quite the contrary way, opening us up to those worlds and revealing to us our inseparability from them. We might say that the boundaries which give the impression of cleaving us apart, simultaneously cleave us together.

This claim becomes more intelligible if we consider the skin with its surfaces within surfaces, with its biological membranes of stratum corneum, epidermis, dermis and subcutaneous tissue, and our sense receptors and nerves; and then the skin has hairs which respond to temperature, which can stand erect if we are suddenly fearful, and which can be brushed by a sleeve or caressed gently by a breeze; and then there are the material membranes of our clothes with their textures and degrees of translucency, and our personal and social boundaries which vary in relation to our culture, our moods and emotions, our confidence, our company, our feeling of well-being and health, and so on. Our natural

\footnotetext{
7 This notion of community and reciprocity is redolent of the A edition version of Kant's (1929) third Analogy where he states that "All substances, so far as they coexist, stand in thoroughgoing community that is, in mutual interaction." (A212).

${ }^{8}$ I do not intend to imply that only human beings can be subjects of experience; there is plenty of evidence to the contrary, see, for example, de Waal and Thompson 2005; human beings are merely the focus of this chapter. One important implication of other animals' also being subjects of experience and values-realising in their activity, is that their activity also bears the hallmarks of the protomoral; but this is an implication to explore at another time.

${ }^{9}$ The interrelation of self and other as a socially- and culturally-embedded phenomenon is a whole other level of cognitive and conceptual description and discussion, and far beyond the sphere of this current piece.
} 
assumption has been to see the boundary of the body as the limit of our experiential world, ${ }^{10}$ but it is precisely its semi-permeable nature, its breach, which provides us with the possibility of experience in the first place. The skin, overrun with an abundance of receptors - sixty kilometres of nerve fibres, fifteen kilometres of veins, with millions of sense receptors for pain, temperature, pressure and touch (Hoffmeyer 2008, p.18) - opens us up to the world and discloses it through our inescapable engagement with it. ${ }^{11}$ The wondrous tactility of touch is supplemented by the visual, proprioceptive, kinaesthetic, auditory, gustatory, and olfactory senses which open us up in their own way, not individually but synaesthetically, holistically, within the community and reciprocity of our living being amongst a vast range of other living beings and things.

Thus it is that we exist as co-affective sensory-kinaesthetic agents who spill over into the lives of others, just as they spill over into ours. It is this capacity to transgress mutable and yielding - boundaries which establishes the community and reciprocity of felt experiential entanglement and provides the grounds from which we can realise our world as value-laden. This experientially entangled co-engagement is fleshed out in meaningful affective bodily dynamics which are, in themselves, value-laden and the necessary precursors of effective affective social, cultural and linguistic communication in the human agent. ${ }^{12}$ Thus our linguistic, and therefore conceptual, claims for our autonomy and individuation depend on our being intersubjectively interrelated from the very beginning; accordingly, we will take a look at the very beginning, with a quotation from Piontelli's pioneering work on prenatal fetal activity (Piontelli 1992 \& 2002).

\section{Pre-Natal fetal activity}

Piontelli's experiential developmental work has involved both singletons and twins, and has involved longitudinal studies carried on from prenatal activity to postnatal activity, and on into adolescence. Her work provides superb examples of the spontaneous somatosensory enquiry which, once begun, continues unceasingly for the lifetime of that organism, and is described by Merleau-Ponty's as an 'intertwining' or chiasm of touch with the tangible (Merleau-Ponty 1968). This intertwining is more than a mere interrelation, for this intertwining possesses both a reciprocal affect and an ambiguous transcendence with its interrogative universe.

\footnotetext{
${ }^{10}$ One of the most notable exceptions to this assumption has been Merleau-Ponty 1962; in Part 1, Chapter 3 he presents a discussion of the pliability of our body's spatiality and sensitivity using, for example, a stick, a car, and a hat with a feather.
}

A woman may, without any calculation, keep a safe distance between the feather in her hat and things which might break it off. She feels where the feather is just as we feel where our hand is. (ibid. p.165)

See also Footnote 2 of Brey 2000 where he claims that Heidegger's “proximally-ready-to-hand” (zunächst zuhanden) predates Merleau-Ponty's claim.

${ }^{11}$ It is touch, for Aristotle, which is our primary sense: "First of all in perception all animals have touch." (Aristotle 1968, De Anima, 4134), but touch also possesses an axiological, or values-realising, edge over the other senses in human practical action (ibid. Chapter 9, Book II); in respect of touch, man, Aristotle claims, is much more accurate than other animals, and it is for this reason 'he' is most intelligent.

12 See, for example, Reid 1769 \& Reid 1983; Cowley 2009; Thibault 2011; Radman 2012; Stuart and Thibault 2015; Stuart 2015. 
Fetuses touch themselves and at the same time are constantly touched by their environment, be it the amniotic fluid, the uterine surface, the placenta, or the cord. They actively touch predominantly through localized motions and are touched when performing other motions, especially generalized motions and when at rest.

From the start, local movements are directed toward particularly sensitive areas of the body abundantly innervated by sensory fibers. The face is the main target, and it is touched with the hands ...Less sensitive areas such as the thorax and stomach are hardly ever touched. (Piontelli 2015, p.378-9)

Three very important things stand out in these two short passages.

The first is the intertwining of fetal senses with fetal world, simultaneously touching and being touched, simultaneously folding itself in on itself and unfolding itself into its world, establishing and maintaining an enfolded congruity or consonance of experiential horizon and action possibility. In this way the whole exists within an "ambiguous transcendence" (Young 1980), an experiential inseparability of the fetus-world-being, a being which is at one and the same time, both subject and object, and neither subject nor object individually. This interrogative 'universe' - fetus-world-being - is fleshed out by Merleau-Ponty when he describes his hands touching one another.

(M)y hand, while it is felt from within, is also accessible from without, itself tangible, for my other hand, for example, if it takes its place among the things it touches, is in a sense one of them, opens finally upon a tangible being of which it is also a part. Through this crisscrossing within it of the touching and the tangible, its own movements incorporate themselves into the universe they interrogate, are recorded on the same map as it ...(Merleau-Ponty 1968, p.133)

The second important thing is that it is certainly interesting, though not at all surprising, that the fetus is naturally more inclined to touch the most sensitive areas of its body, especially the head and hands, because it is from these sensitive areas that its action-enquiry gets the most immediate reply. ${ }^{13}$ And it is no surprise that these areas are the most prominent on the cortical homunculus in the "Penfield map" (Penfield 1958). It is also interesting that these areas of heightened sensitivity are those used most effectively to communicate pre-lingually in the post-natal infant, or even post-lingually when we are, for example, trying to communicate in a country where the native language is unfamiliar to us. From the outset we feel our way with our world, making sense and grasping meanings feelingly; opening up possibilities of being which, in its present continuous sense, are also the organism's becoming.

Thirdly, Piontelli, speaks of this affectively-driven intertwining as "directed toward", which implies intentionality, preference, and the realisation of some affective value in the action; thumb-sucking meets all three criteria. Thus, the fetus-world-being is characterized by being inherently intentional, which is to say that being-with and

\footnotetext{
${ }^{13}$ It would be interesting to monitor the repetition of such pre-natal action-enquiries to see if they make the gradual shift towards kinaesthetic habits, and then to see how many of these bodily habits carry over into post-natal activity. One would imagine that the relatively long-established fetal bodily habits which carry on post-natally may be the most comforting and reassuring; which is exactly the right incentive for continuing with them; thumb-sucking may be the prime example of just such a mouth-hand intertwining which continues post-natally.
} 
being-among is necessarily relational and comes already clothed in 'aboutness'; so, the fetus's action-enquiry within its interrogative universe is intentionallysaturated from the start. ${ }^{14}$

In precisely this context Trevarthen and Reddy (2007) argue that we continue to fail to accept somatosensory activity as a form of pre-conceptual thought and enquiry, simply because we are drawn to the analytically appealing habit of framing a "categorical division between the intentional or mental and the physical or behavioral" (Trevarthen and Reddy 2007, p.54). They echo Piontelli's description of the prenatal infant's pre-propositional, pre-reflective, pre-conceptual thinking, as an affectively rich meaning-making which begins pre-natally at about eleven weeks:

Human fetuses tentatively touch the placenta, umbilicus and the uterine wall with their hands at 11 weeks. They make jaw movements and swallow amniotic fluid, expressing pleasure or disapproval at tastes injected into it by sucking and smiling or grimacing with disgust. Complex movements of trunk, arms and legs position the body, and may react to the mother's body movements and the contractions of the muscles of her uterus (Lecanuet et al. 1995; Piontelli 2002; Trevarthen et al. 2006). (Trevarthen and Reddy 2007, p.53)

So, throughout its development the fetus - bursting into life - folds into its world as it unfolds in its sensuous action-enquiry, incorporating sensations of touch, temperature, pain, hearing, balance and orientation, the chemosensors of smell and taste, mouthing, sucking, licking and grasping, as a means of exploration of the textures, hardness, and contours of whatever it encounters, including its own body and, in the case of twins, the other's body too. At this time, mouthing, sucking, licking and grasping cannot be involved with eating and nutrition, so, just like the other sensory modes of activity, they are affective somato-sensory kinaesthetic means of exploration which establish, for the prenate, its first field of values. ${ }^{15}$

This interrogative intertwining of fetus-world-being is much more than an underspecified intersubjective interrelation. For a start it possesses an implicit intricacy in which world and fetus are experientially inseparable, and this implies an ambiguous transcendence of fetus and world, where they are both immanent in the pre-reflective experiential entanglement. This immanence implies that being-with-world ${ }^{16}$ is a natural, even necessary or transcendental, condition of our being at all; and if this is the case, our capacity for intentional transgression - spilling over into the world and passively and spontaneously being affected by the world - is also a natural, even necessary or transcendental, condition of our living being within the community and

\footnotetext{
${ }^{14}$ Husserl speaks of the hyle or hyletic as the sensuously palpable affection in a temporal horizon of subjective bodily living (Husserl 1982, §85, pp.203-7), but his account of the relational dialogue is inconsistent for he denies sensuous intentionality: "the sensuous, which has in itself nothing pertaining to intentionality" (ibid. p.203). If he were correct that the hyletic core affection is non-intentional, the organism would be unable to establish kinaesthetic memories, melodies, and anticipations but, much more seriously it would be ineffective socially, unable to engage enkinaesthetically through the "passive synthesis" of affective enfolding.

${ }^{15}$ For a thorough and engaging discussion of values, affordances, and value fields, see Hodges (2007), Hodges and Baron (1992), and Steffensen and Hodges (2010).

${ }^{16}$ Elsewhere I refer to this as the Mitseinwelt (see, for example, Stuart 2010a, b, 2011, Stuart 2012, 2013, \& Stuart 2015, \& Stuart and Thibault 2015).
} 
reciprocity of affectively-laden action-enquiry. So, now I will go further and claim that, without our capacity for intentional transgression there would be no ambiguous transcendence of our being-with-world, and without our capacity for ambiguous transcendence, there would be no possibility of establishing kinaesthetic memories, melodies, or the anticipatory dynamics which prepares us for expectation, the possibility of being confounded, and the need for adaptation, and furthermore, we would be unable to develop the empathy that is crucial for our social cohesion and well-being.

Before we proceed, let's summarise our conclusions, introduce more formally a shorthand term for this intricate affective interrelation, and then move on to present some pre- and post-natal evidence for the affective attunement of intersubjective intentional transgression.

All action is sensuous action-enquiry within the agent's experiential horizon. Experiential horizons aren't limited by the pseudo-boundaries of skin or clothes, indeed the breach that they afford opens the agent up to its intersubjective and interobjective ${ }^{17}$ world. The intricacy of the interrogative intertwining of agent and world reveals the liberty of the agent's intentional transgression which creates an ambiguous transcendence and a chiasm of world and agent. Thus the world has an experiential immanence for the agent. But, because it would be the stuff of nightmares to explain the affective intricacy of this relationship every time we wanted to refer to it, I'm going to introduce an abbreviation, the term 'enkinaesthesia'.

\section{Pre- and post-Natal Enkinaesthetic dialogue}

In this section I will offer support for the claim that within enkinaesthetic action-enquiry we can have the immanent experience of the implicit, and, sometimes, explicit intentional co-agency of the other. The intentional transgression necessary for this comes about in a similar way to the fetal-world-being already discussed, but in enkinaesthetic intersubjectivity ${ }^{18}$ we place additional emphasis on "affect attunement as the primary bio-discourse of social creatures" (Willett 2014, p.92). It is through affect attunement (Stern 1985) that we can establish enkinaesthetic prosodies of resonance and fragmentation which are "regulated by emotions of affection and enjoyment, expressed and given meaningful form by rhythms of modulated movement" (Malloch and Trevarthen 2009 , p.2). One way to think of these enkinaesthetic prosodies is as the affective cadences of living co-experience, for it is only through the natural attunement and fragmentation of these cadences that we learn to anticipate the intentional trajectory of the other's action and they ours. But let's take a step back for a moment and consider three different studies which support the occurrence of enkinaesthetic attunement of coaffective activity: synrhythmic regulation, altriciality, and pre- to post-natal twins.

There is a growing body of evidence to show that, within pregnancy, mother and prenate, and, occasionally, mother with two or more prenates, prenate with prenate in the case of twins, and prenates with their bodies and the surrounding amniotic environment, form a synrhythmic regulation of their heartbeats and their respiratory

\footnotetext{
${ }^{17}$ Objects can also affect us, for example, the presence or absence of a treasured possession affects us in very different ways. Interobjectivity is a crucial aspect of our lived and living experience, but it is not characterised by a reciprocity of affect, and it is not the concern of this essay.

18 There are few instances of non-enkinaesthetic intersubjectivity, but the most obvious might be psychopathy. However, this is largely conjectural and much more work needs to be carried out in this context.
} 
system $^{19}$; where 'synrhythmia' refers to the reciprocal co-regulation of interoceptive systems, which creates an affective experience of well-being.

In each environment the vitality of the child is dependent on regulations across a succession of 'frontiers' with the human world, first physiological or amphoteronomic, then by the special direct psychological communications which we define as synrhythmic, and finally by sharing symbolic awareness of culture and language. (Trevarthen et al. 2006, p.69)

Though I disagree with Trevarthen's separation of mind and brain, I agree with the sentiment he expresses when he says that "volitional and experiential functions of the minds of infant and mother (are coupled) through sympathetic response of their brains to the anatomical forms and dynamics of movement in structures of their body" (Trevarthen et al. 2006, p.107). Perhaps a more compelling way to phrase this would be in terms of the enkinaesthetic co-affectivity which constitutes the sympathetic response, not of brains, but of a being that is always being-with. ${ }^{20}$ Thus, the givenness of the fetus or infant's experience is never in isolation from the givenness of the mother or other care-giver's experience. We could even go so far as to say that their experience operates and, what's more, it can only operate as an enkinaesthetic intertwining. The fetal-world-being includes much more than just its body and the inside of the mother's womb, it includes the mother's anatomical form and activity, her humours and hormones, and the dynamic movements of her body, and her body exists within its own universe of enkinaesthetic intertwinings. The emphasis on enkinaesthetic co-affectivity in fetal-world-being and infant-world-being lends support to Emde's claim for the "emotional availability" of the organism (Emde 1980) but at a much more pragmatic level of affect attunement, that is, as the primordial bio-dynamic discourse.

So, pre-natally this primordial enkinaesthetic discourse is evident in the synchronization of fetal-maternal heartbeat:

The fetal heart rate, a primary accessible indicator of prenatal development, changes with the physiological and psychological state of the mother: fetal heart rate variability and body movement substantially decrease with hypooxygenation of maternal arterial blood; increased maternal stress and anxiety levels correlate with increased mean fetal heart rate (Monk et al. 2000); during the night the mean hourly fetal heart rate decreases in synchrony with the mean maternal heart rate (Patrick et al. 1982). This correlated behavior in the mean heart rates suggests certain coupling between the cardiac systems of mother and fetus. However, there has been no evidence of maternal-fetal heartbeatto-heartbeat coordination, until now. (Ivanov et al. 2009, p.13641)

The continuity of action from pre-natal to post-natal life is now widely accepted and, both naturally and of necessity, this primordial enkinaesthetic discourse must carry on post-natally. As nidicolous infants, unable to "fly the nest" immediately after birth or, indeed for some very long time, we are altricial, dependent on others for nourishment, nurture, and protection

\footnotetext{
${ }^{19}$ See, for example, the fascinating work of Van Leeuwen et al. 2009 on fetal-maternal heartbeat synchronization.

${ }^{20}$ Trevarthen comes very close to this when he describes it as "A delicate and immediate with-the-other awareness". (Trevarthen 1993, p.122)
} 
from potential threats. Dissanayake claims that it is "because of increasing infant altriciality during hominization, (that) the primate propensity for relationship or emotional community, not just sociability, became so crucial that special affiliative mechanisms evolved to enhance and ensure it" (Dissanayake 2000, p.389). One such affiliative mechanism is our natural propensity for the formation of enkinaesthetic prosodies - resonances and fragmentations of resonances - of the affective cadences of living co-experience; prosodies which can now be observed in the enkinaesthetic activity and progress of pre- to post-natal twins.

Luca and Alice were temperamentally different before and after birth, though they were gentle and affectionate with each other in both periods. Luca was smaller, more active, and the first to be born. They stroked each other gently in utero, just as they later stroked each other from either side of the curtain when they were a year old....

Giorgio and Fabrizio had a very unusual experience in utero because they shared not only the same genoma but also the same amniotic sac, so that they were intertwined and mixed up with each other throughout their uterine life. Fabrizio was usually the first to move, to be followed a moment or two later by Giorgio, a pattern that is still noticeable at four years of age. (Piontelli 1992, p.235-6)

Alice and Luca, Fabrizio and Giorgio manifest the interrogative intertwining of fetal senses in a way which reveals, at least, one crucial difference from a singleton's pre-natal experience. Luca's exploratory touch meets Alice's, and Alice's meets Luca's, they each have their feeling interrogation of their world met by the other's reciprocal feeling interrogation, thus it seems likely that the enkinaesthetic feel of their intertwining will have a distinct affective quality that will be absent in a singleton's fetal-world intertwining. In the twins' case, their non-propositional intentional affective enquiry is met by non-propositional intentional affective enquiry, that is, they each feel the agency of the other in their reciprocal intertwining. For the singleton their meaning-making and values-generation exist in the intricacy of the affective fetus-world-being chiasm; but for the twins they exist with the additional intricacy of a primary ${ }^{21}$ intersubjectivity, a more explicit sense of their world that is active, not just in its response but in its own enquiry. ${ }^{22}$

The ambiguous transcendence experienced by Fabrizio and Giorgio may be all the more intense because they shared the same amniotic sac; they have not yet experienced separation, indirectness and distance. In Alice and Luca's case they seem to try to recreate the pre-natal immanence of the other in experience by each stroking the other from the other side of a curtain. We cannot be sure that the curtain is replacing the pre-natal experience of the amniotic sac, but we can be sure that Alice and Luca have, in this game, reduced the visual experience and emphasised once more the primordial sensation of touch. Their reciprocal stroking action is evidence of reciprocal touch, but the reciprocation cannot be visually-instigated 'mirrored' action because they have yet to form a visual sense; this points to something really interesting. The preponderance of neurons in the rostral part of the inferior parietal lobule (PF) are

\footnotetext{
${ }^{21}$ The notion of 'primary intersubjectivity' is introduced here merely to denote the necessarily social pre-natal circumstance of twins (or other multiples). It is not a synonym for 'enkinaesthesia'.

${ }^{22}$ It's conjecture at this stage, but perhaps this enkinaesthetic intertwining of fetus with fetus and the resulting ambiguous transcendence, goes some way to explain the close bond, and even inseparability of twins after birth.
} 
somatosensory, ${ }^{23}$ and according to Rizzolatti et al. (2001) action imitation is not the primary function of the mirror neuron system, rather it is the basis for action understanding. Given that this is the case, the enkinaesthetic affect-attunement and fragmentation of the twins' pre-natal enkinaesthetic entanglement is an extraordinarily fertile ground for:

- forming somatosensory habits which can continue post-natally;

- making sense and grasping meanings feelingly;

- opening up possibilities of being and becoming;

- realising values and establishing future values; and

- communicating affiliative intent.

With the exception of the communication of affiliative intent - which requires an other, these affectively-rich actions will also be true for the pre-natal singleton. They are the most primitive of the organism's enkinaesthetically entangled, intentionally-saturated, values-realising actions, yet they manifest the protomoral source of subsequent reflective moral concepts and action. They are, I maintain, the deep roots of morality.

\section{Enkinaesthesia, not empathy}

Our enkinaesthetically entangled action-enquiry may be pre-conceptually intentional, but it is not pre-semantic. Action realises, and sometimes fails to realise a pragmatic, by which I mean nurturing, nutritive, or protective value for the agent, and it is in this values-realisation that the affective action becomes part of the pre-conceptual yet meaningful experiential landscape or Lebenswelt for that agent. In this way the capacity for enkinaesthetic dialogue is a necessary condition for agency and the generation of a felt anticipatory dynamics both within and between agents. ${ }^{24}$

So, enkinaesthetic theory emphasises the way in which our experience of our neuromuscular activity comes already blended with the co-affective feeling of the presence of the other (agential and non-agential alike), and the enkinaesthetically anticipated arc of the other's intentional action when the other is also a living, breathing, sensing agent. ${ }^{25}$ It is our affective intentional reciprocity with the other which emphasises the dialogical nature of our feeling of being-with or being-among, and demonstrates the paucity of individuating notions that treat agents as singular, or worse still as disembodied and denatured (Goldman and De Vignemont 2009). ${ }^{26}$ With it enkinaesthetic theory brings a means of drawing

\footnotetext{
${ }^{23}$ The proportions are: $33 \%$ are somatosensory, $11 \%$ are visual, and $56 \%$ are bimodal (somatosensory and visual) (Rizzolatti and Craighero 2004, p.172).

${ }^{24}$ See also Stuart (2012) and Stuart (2015).

${ }^{25}$ Ed Tronick claims something very similar when, in talking about intersubjectivity as an exchange of meaning, he says "in the infant-adult interaction there is a mutual apprehension in which each understands what the other intends" (Tronick 2007, p.11). This mutual apprehension is a pre-conceptual, pre-reflective understanding which oscillates between harmony and messiness, where 'messiness' is characterised as "a mismatch of the affective states and relational intentions that occur ... when the infant and adult ...convey ...non-matching meanings" (ibid.).

26 "The idea of a separate individual is based, in a quite paradoxical way, on the naive apprehension of what, as Heidegger put it in a lecture in 1934, 'is perceived from outside', what is 'graspable and solid', that is, the body: 'Nothing is more familiar to us than the impression that man is an individual living being among others and that the skin is his boundary, that inwardness is the seat of experiences and that he has experiences in the same way that he has a stomach and that he is subject to various influences, to which he responds."' (Bourdieu 2000, p.131-2)
} 
together how we articulate our concerns and the concerns of others within the sensitive community and reciprocity of living being, ${ }^{27}$ where each action, already characterised by its givenness and a saturated intentionality, engenders affect and that affect engenders action, not just within ourselves but within all life. Under this interpretation we experience and understand our world feelingly before we experience it cognitively, and crucially, that enkinaesthetic feeling action-enquiry continues as our primary mode of discourse even after the advent of language with its conceptualisation of the content of our experience, and its assumption that the cognitive supplants all other forms of thinking. ${ }^{28}$

When characterised as a natural openness to, and reception of, myriad subtle multidirectional cues within an affective community and reciprocity of other plenisentient living organisms and things, enkinaesthesia becomes the primordial mood of being, "a condition of sense for any encounter with beings, whether theoretical or practical" (Ratcliffe 2002, p.289). The greater part of these reciprocal interactions occurs preconceptually as a result of pre-reflective somato-sensory "operative intentionality" (Merleau-Ponty 1962, p.xviii), a form of intentionality characterised by immediacy and spontaneity, and which MerleauPonty explains as a kind of "primordial expression", a wisdom and competence common to all people (Merleau-Ponty 1964) and known pragmatically through the living, breathing community and reciprocity of affective effective co-engagement. ${ }^{29}$

Husserl, who is concerned with the genetic origins of thought, describes this pragmatic competence, in which the agent anticipates, imagines, and enacts its pre-conceptual expectations of how it assumes its world will continue to be, as involving a "passive synthesis". ${ }^{30}$ Such pre- or non-linguistic pre-conceptual somato-sensory, kinaesthetic sense-making is the mark of our practical bodily enkinaesthetic engagement with our world. Some simple examples would be the rhythm or momentum and muscular expectation we build up when practising scales or arpeggios on the piano, or when walking on a moving walkway in an airport, or when walking down a moving, descending escalator. We spontaneously and passively synthesise the plenisentient experience so that we can establish a harmonious enkinaesthetic prosody of action with our changing world. In this way we create and maintain a fluidity of action until we are distracted and our fingers stumble on the keys, or the walkway comes to an end, or the escalator stops unexpectedly. And, once the harmony fragments we are forced to perform a more active, and possibly, thought-full synthesis in an effort to re-establish the previous concordant enkinaesthetic melodies or to endeavour to create new ones; in all events the impulse to re-establish an affective prosody of action is normatively driven and values-realising.

Thus we exist in a continuous flow of the creation and fragmentation of agentialkinaesthetic, interpersonal, intersubjective, intercorporeal, enkinaesthetic melodies, and whilst it is true that enkinaesthetic theory provides explanatory grounds for the phenomena of emotional contagion and the ability to adopt another perspective reasons enough for it to be fundamental for ethical engagements and necessary for

\footnotetext{
${ }^{27}$ This notion of community and reciprocity is redolent of the A edition version of Kant's third Analogy where he states that "All substances, so far as they coexist, stand in thoroughgoing community, that is, in mutual interaction." (A212).

${ }^{28}$ See, for example, Carruthers (2005) and Rosenthal (2005) for accounts from this perspective.

29 'Effective' is emphasised because effective action will have a greater value for the agent than ineffective action and, thus, a greater chance of becoming a habituated practice, ease-fully carried out, spontaneous in its application, implicit, passive, and backgrounded.

${ }^{30}$ See, particularly, Husserl 1966 and Husserl 2001.
} 
the derivation of moral laws - it is not simply empathy by another name. There are three reasons for this, all mentioned only briefly here. Firstly, enkinaesthesia is primordial, it's there from the outset, as we have seen with the pre-natal fetus-world-being and the enkinaesthetic intertwining of fetus with fetus, but empathy is a much later evolutionary (possibly cultural) development amongst social animals, particularly humans. Secondly, we have also seen that the individual at a sub-personal level is never an individual, for at this level of explanation the agent is a co-constituent of an enkinaesthetically coordinating, values-realising situation. And thirdly, current work in empathy, even at the lowest level of its conception as spontaneous and unreflective motor mimicry (de Waal and Thompson 2005) fails to prioritise the situation over the individual. ${ }^{31}$

To bring these three criteria into the foreground we'll examine the affective perturbation felt by mother and infant, particularly the infant - after all the mother is a confederate and can understand what is happening even if she doesn't enjoy it - created by the "Still Face" experiment (Tronick et al. 1978; Tronick 2007; Tronick and Beeghly 2011).

\section{Enkinaesthetic absence: Becoming invisible}

The classic Face-to-Face Still-Face paradigm confronts young infants with three successive interactive contexts: 1) a "normal" face-to-face caregiver-infant social interaction during which the caregivers are asked to play with their infants in a normal manner, followed by 2) a still-face episode during which caregivers are instructed to keep an unresponsive poker face and not to smile, touch, or talk to their infants, followed by 3 ) a reunion episode during which the caregivers and infants resume normal face-to-face social interaction. Each episode typically lasts 2-3 minutes with 2 minutes being the modal length. (Weinberg et al. (2008), p.5)

The second and third contexts of this experiment are very difficult to watch ${ }^{32}$ and the transcripts are difficult to read ${ }^{33}$ because the infant's response to a completely unanticipated blank disengagement is swift and desperate. I will describe one instance of the experiment, but the pattern of infant reaction is consistent in all cases.

The infant begins by smiling at the mother in the hope that she will elicit a response; none is forthcoming. The infant now points in an attempt to redirect the mother's attention to something they can jointly share, but this also fails. The infant then leans forward and gestures with arms outstretched to be picked up; again nothing, and the infant falls backwards. She waves and claps her hands, clasps them together, brings them

\footnotetext{
${ }^{31}$ A quotation from Weinberg et al. (2008) demonstrates the prioritisation of the individual even in dyadically organised or co-created meanings.
}

Meanings are both self-organized (regulated internally and private) and also dyadically organized (regulated with others and shared). When meanings are dyadically organized, a dyadic state of consciousness emerges between the individual-something akin to Vygotsky's zone of proximal development (Vygotsky 1967). These dyadically organized meanings contain new co-created meanings that, in turn, can be appropriated by each individual into his own private state of consciousness. (p.5)

32 See, for example: https://www.youtube.com/watch?v=apzXGEbZht0

${ }^{33}$ See Weinberg et al. (2008), pp.11-4, though to avoid confusion I should point out that the transcripts are from the studies with toddlers of two-and-a-half years, and not from the earlier 'classical' infant studies. 
to her mouth, and screeches in an attempt to break the deadened-affective impasse. She reaches out one last time and then falls back in on herself. Finally, she looks away from the mother and collapses in tears of distress. The infant, without the co-affective intentional transgression of the mother is now in extreme discomfort. In fact, 'discomfort' may be too mild a word to describe her experience because studies now reveal that they manifest a full range of autonomic behavioural stress indicators such as spitting up and hiccuping (Weinberg and Tronick 1996, p.908), heart, respiratory sinus arrhythmia, skin conductance, vagal tone, and cortisol changes (Bazhenova et al. 2001; Haley and Stansbury 2003; Tronick 2007). The infant is thoroughly wretchéd.

For the infant, the loss of their primordial discourse, in the form of the mother's co-affective reciprocity, provokes a sudden existential crisis. The enkinaesthetic intentional transgression which has made intersubjective meaning possible has vanished, and without warning. In its place there is only dissonance and bewilderment, followed by more and more urgent attempts to re-establish affectively familiar positive rhythms and restore some equilibrium. When every strategy fails the infant, having experienced an enforced individuation, now suffers the anguish of a seemingly unending fragmentation with no anticipated means of resolution. At which point, but only because this second context has come to an end, the mother moves forward and speaks to soothe the infant, and the pair enter the reunion phase of the experiment. One might expect a mighty relief on the infant's part, a swift and joyful reunion, and the re-establishing of resonance, but it is not so straightforward. There is, in this phase, a "reunion effect" with increased negativity, demonstrated by facial expressions of anger and sadness, crying, gaze aversion, and a continued focusing on objects and not the mother's face. In the latter case, a temporary preference for the the stability of interobjective engagement can be understood as restorative of some balance in the autonomic nervous system, especially because the infant cannot be sure that when she looks back at her mother she will be affectively responsive. In seeking the object the infant is realising a non-social value and, following a traumatising situation, one might be concerned that the infant's desire for interobjectivity becomes a somatosensory habit and a norm within their protomoral discourse.

The reunion episode is thought to be stressful for dyads because the mothers and children must re-establish and repair the interaction following the still-face. The reunion episode therefore presents dyads with an affectively complex and demanding regulatory meaning-making task of coming to a renewed shared meaning about what they are doing together. Infants must simultaneously cope with the resumption of maternal behavior and with the intra- and interpersonal carry-over of negative affect and stress from the still-face that was generated by the senselessness of the mother's unresponsive behavior during ...(Weinberg et al. (2008), p.6)

Now, if it is through the natural attunement and fragmentation of these cadences that we learn to anticipate the intentional trajectory of the other's action, in this experiment - as in many everyday circumstances - the infant has learnt that it is unable to trust its anticipations of its mother's experience and action. Furthermore, we now know that being soothed after being distressed or fearful doesn't simply reset the infant's system to its pre-experimental 'settings', that once the possibility of incoherence has entered the infant's experience, the infant is primed to anticipate, and fear, its arising again. In fact, in a recent study Montirosso et al. (2013) have shown that a four-month-old infant, who has experienced disengagement and neglect within the Still Face experiment, will 
have a two-week memory of it, producing the same negative responses - the production of the stress hormone cortisol, an increase in heart rate, and so on - when anticipating the same kind of fragmenting and alienating experience. ${ }^{34}$.

Thus, in an alienating and distressing experience, like the one presented in the Still Face experiments, there is a profound enkinaesthetic collapse, a radical and extreme enkinaesthetic disintegration brought on by the cessation of affective intertwining, and the subsequent failure of the infant's sense-making action-enquiries. The mother's activity is, for the infant, sense- or meaning-less. We might think of this in terms of the spontaneous passive experiential synthesis that mother and infant had naturally brought forth together before the experiment, but which has now been confounded just like when our fingers stumble on the piano keys in our performance of the arpeggio - and the mother and infant reunion episode must be a much more effortful active, thought-full synthetic process. ${ }^{35}$ The effort to re-establish the previous concordant enkinaesthetic melodies is normatively driven, in the sense that it is an attempt to reintegrate the fragmented elements and realise a nurturing and protective value for the infant and an intertwined well-being for the pair, but it is not spontaneous and easeful. It only takes a two-minute suspension of an infant's critical enkinaesthetically intricate entanglement with its mother to induce a feeling of acute debilitating stress, and, given that, in that time, she is unable to anticipate the mother's intentional trajectory and act appropriately, it may even introduce an anticipation anxiety about what can be expected reliably from the mother's - and subsequent others' - future actions.

Were this experience to be extended or become frequent the infant's experience would be perfused with a toxic stress, and even more so if there continued to be, not just the negligent absence of parental support, but a deliberate non-engagement by the parent. To cease to feel the other immanent in your experience is also to synchronously lose ourselves as immanent in their experience. It is to feel our skin tighten around us and lose its natural breach. It is to lose our natural intentional transgression and our feeling of our ambiguous transcendence and to be thrown back on ourselves, alone.

Children who experience chronic, severe stress may be biologically and psychologically less able to adapt and cope with new stresses when they occur, contrary to the idea that regular stress toughens people and increases their resiliency. (Thompson 2014, p.49)

Social exclusion is painful, actually physically painful (Leiberman and Eisenberger 2005), and that pain tends to diminish the urge towards prosocial behaviour, and, if the social exclusion persists, the person can even become more inclined to act maliciously (Twenge et al. 2001; Twenge et al. 2007).

So, we know that "Persons and contexts are not static, orthogonal effects, but are instead in dynamic interaction. Changes on one side of the interaction invariably induce a cascade of consequences on the other side. Both are mutually implicative in accounting for behavior." (Lapsley and Narvaez 2004, p.194), but we can also now recognise that the 'interaction' spoken of here is very conservative. Our being is always a being-with, we are never alone, though we can be alienated and made to feel alone. Our natural being is within a co-affective

\footnotetext{
${ }^{34}$ See also Grant et al. (2009).

${ }^{35}$ By 'thoughtful' I do not mean 'propositional'; see Stuart 2015.
} 
enkinaesthetic entanglement of co-agential living being and becoming, which is to say that it always possesses a protensional anticipatory dynamics. Lapsley \& Narvaez claim that our sense of our personal coherence emerges from the "reciprocal interaction between the dispositions, interests, capacities, and potentialities of the agent and the changing contexts of learning, socialization and development" (ibid.), and to a large extent I agree, but they are talking at a personal and individuated level. From an enkinaesthetic and protomoral perspective, our personal coherence emerges only through our enkinaesthetic coherence; we might say that an enkinaesthetic consonance with my world creates an enkinaesthetic consonance with myself, and if I am made to feel cut off from my world, I am likely to feel cut off from myself. In the Still Face experiment the infant is made to feel socially invisible; if it happens often enough, the social will become invisible to the infant.

\section{Rounding up}

We will round up our discussion by going back briefly to the deep roots of morality: the enkinaesthetically entangled, intentionally-saturated, values-realising actions which manifest the protomoral source of subsequent reflective moral concepts and action; and we can now see that the second phase of the Still Face experiment violates each of these actions.

The communication of affiliative intent is blocked by the mother's blank unresponsiveness, and the infant falls back on somatosensory habits of engagement, pointing to direct and share in the mother's gaze, and then to self-orientated somatosensory habits, like clasping and chewing their hands. Without affiliative entanglement the infant's affective sense-making is compromised; again it turns inward and seeks respite in interobjective engagement. The failure of the enkinaesthetic intentional transgression, that had made the infant's anticipation of the mother's intentional trajectory so successful, now makes it impossible to open up possibilities of being-with which will simultaneously be possibilities of. Yet even at such an impasse, when there is only enkinaesthetic fragmentation, it may be possible to realise a value and establish a future value, and in this case it might be to embody - pre-reflectively - new somatosensory habits which will avoid such a breakdown happening again. Our capacity for adaptivity is phenomenal, unless the stress is truly toxic.

\section{Conclusion}

I have attempted to demonstrate that it is through enkinaesthetic 'mind'-feeling dialogue that values-realising activity originates. I have argued that the capacity for enkinaesthetic dialogue is an a priori nomological condition for agency and the generation of a felt anticipatory dynamics both within and between agents. It is not empathy, but it is a necessary requirement for empathy. In arguing for this I hope to have demonstrated how deeply felt enkinaesthetic melodies, both resonating and fragmentary, emphasise the dialogical nature of the feeling of being as the feeling of being-with or being-among, and to have demonstrated the paucity of individuating notions that treat agents as singular and autonomous. Our enkinaesthetic protomoral dialogue exists in the essential intertwining of our action-enquiry and meaning-making, for only then, and with the advent of concepts, can the monologue of the individuated moral agent arise. 


\section{Afterword}

On looking back at The Tree of Knowledge: The Biological Roots of Human Understanding (Maturana and Varela 1992) I am motivated to paraphrase a claim made by Maturana and Varela: "Nothing [I have said] will be understood in a really effective way unless the reader feels [has felt] personally involved and has a direct experience that goes beyond all mere description." (p.18). Their claim about cognition being a "bringing forth of a world through the process of living" (p.11) is consistent with my own claim that through enkinaesthetic values-realising activity a proto-moral world is brought forth, but it is their appeal to feeling involvement which is fundamental.

Open Access This article is distributed under the terms of the Creative Commons Attribution 4.0 International License (http://creativecommons.org/licenses/by/4.0/), which permits unrestricted use, distribution, and reproduction in any medium, provided you give appropriate credit to the original author(s) and the source, provide a link to the Creative Commons license, and indicate if changes were made.

\section{References}

Aristotle. (1968). De Anima Books II \& III, D. W. Hamlyn trans. Oxford: Oxford University Press.

Bazhenova, O. V., Plonskaia, O., \& Porges, S. W. (2001). Vagal reactivity and affective adjustment in infants during interaction challenges. Child Development, 72(5), 1314-1326.

Bennett, J. (2010). Active power in general (Thomas Reid), early modern texts. http://www.earlymoderntexts. com/assets/pdfs/reid1788essay1.pdf. Accessed 23 Apr 2017.

Bourdieu, P. (2000). Pascalian Meditations, trans. Richard Nice: Stanford University Press, Stanford, California.

Brey, P. (2000). Technology and embodiment in Ihde and Merleau-Ponty. In C. Mitcham (Ed.), Metaphysics, Epistemology, and Technology. Research in Philosophy and Technology Vol.19 (pp. 45-58). London: Elsevier/JAI Press.

Carruthers, P. (2005). Consciousness: Essays from a higher-order perspective. Oxford: Oxford University Press. Cole, J. D. (1991, 1995). Pride and a Daily Marathon. London: MIT Press.

Cotterill, R. M. J. (1995). On the unity of conscious experience. Journal of Consciousness Studies. Imprint Academic., 2(4), 290-311.

Cotterill, R. M. J. (1998). Enchanted looms: Conscious networks in brains and computers. Cambridge University Press.

Cowley, S. J. (2009). Distributed language and dynamics. Pragmatics and Cognition, 17(3), 495-507.

de Waal, F., \& Thompson, E. (2005). Primates, monks and the mind. Journal of Consciousness Studies, 12(7), 38-54 (interviewed by Jim Proctor).

Dissanayake, E. (2000). Antecedents of the temporal arts in early mother-infant interaction. In N. Wallin, B. Merker, \& S. Brown (Eds.), The origins of music. Cambridge, MA: MIT Press.

Emde, R. (1980). Emotional availability: A reciprocal reward system for infants and parents with implications for prevention of psychosocial disorders. In P. M. Taylor (Ed.), Parent-infant relationships (pp. 87-115). Orlando, FL: Grune \& Stratton.

Fodor, J. (2008). LOT 2: The language of thought revisited. Oxford University Press.

Forget, R., \& Lamarre, Y. (1987). Rapid elbow flexion in the absence of proprioceptive and cutaneous feedback. Human Neurobiology, 6(1), 27-37.

Gibson, J. J. (1979). The ecological approach to visual perception. Boston: Houghton-Mifflin.

Goldman, A., \& De Vignemont, F. (2009). Is social cognition embodied? Trends in Cognitive Sciences., 13(4), 154-159.

Grant, K.-A., McMahon, C., Austin, M.-P., Reilly, N., Leader, L., \& Ali, S. (2009). Maternal prenatal anxiety, postnatal caregiving and infants' cortisol responses to the still-face procedure. Developmental Psychobiology, 51(8), 625-637.

Haley, D. W., \& Stansbury, K. (2003). Infant stress and parent responsiveness: regulation of physiology and behavior during still-face and reunion. Child Development, 74(5), 1534-1546.

Henry, M. (1963). L'Essence de la manifestation/the essence of manifestation (p. 1973). The Hague: Nijhoff. 
Hodges, B. H. (2007). Values define fields: The intentional dynamics of driving, carrying, leading, negotiating, and conversing. Ecological Psychology, 19(2), 153-178.

Hodges, B. H., \& Baron, R. M. (1992). Values as constraints on affordances: Perceiving and acting properly. Journal for the Theory of Social Behaviour., 22(3), 263-294.

Hoffmeyer, J. (2008). Biosemiotics, An examination into the Signs of Life and the Life of Signs, trans, $J$. Hoffmeyer \& D. Favareau. Scranton and London: University of Scranton Press.

Husserl, E. (1966). In M. Fleischer (Ed.), Analysen zur passiven Synthesis. Aus Vorlesungs- und Forschungsmanuskripten, 1918-1926. The Hague: Martinus Nijhoff.

Husserl, E. (1982). Ideas pertaining to a pure phenomenology and to a phenomenological philosophy. Dordrecht: Kluwer Academic Publishers.

Husserl, E. (2001). Analyses Concerning Passive and Active Synthesis. Lectures on Transcendental Logic. (trans. Anthony J. Steinbock). Dordrecht: Kluwer Academic Publishers.

Ivanov, P. C., Ma, Q. D. Y., \& Bartsch, R. P. (2009). Maternal-fetal heartbeat phase synchronization. Proceedings of the National Academy of Science, USA., 106(33), 13641-13642.

Jeannerod, M., Michel, F., \& Prablanc, C. (1984). The control of hand movements in a case of hemianaesthesia following a parietal lesion. Brain, 107, 899-920.

Kant, I. (1787/1929). The Critique of Pure Reason. (trans. Norman Kemp Smith). London: Macmillan and Co., Limited, St. Martin's Street.

Lapsley, D. K., \& Narvaez, D. (2004). A social-cognitive approach to the moral personality. In Moral development, self and identity. (edited by D. K. Lapsley \& D. Narvaez) (pp. 189-212). Mahwah, NJ: Erlbaum.

Lecanuet, J.-P., Fifer, W. P., Krasnegor, N. A., \& Smotherman, W. P. (Eds.). (1995). Fetal development: A psychobiological perspective. Hillsdale, NJ: Erlbaum.

Leiberman, M. D. \& Eisenberger, N. I. (2005). A pain, by any other name (rejection, exclusion, ostracism), still hurts the same: The role of dorsal anterior cingulate cortex in social and physical pain. In Social Neuroscience: People Thinking About Thinking People. (Edited by Cacioppo, J. T., Visser, P. S. \& Pickett, C. L.). 167-88.

Locke, J. (1844). Locke's essays: An essay concerning human understanding, and A treatise on the conduct of the understanding Complete in 1 volume with the author's last additions and corrections. Philadelphia: James Kay, Jr, \& Brother (First published 1689, though dated 1690.)

Malloch, S., \& Trevarthen, C. (Eds.). (2009). Communicative musicality. Oxford: Oxford University Press.

Maturana, H. R., \& Varela, F. (1992). Tree of Knowledge: The biological roots of human understanding. Boston: Shambhala.

Merleau-Ponty, M. (1962). Phenomenology of perception. New York: The Humanities Press. (Trans. Colin Smith). London: Routledge and Kegan Paul.

Merleau-Ponty, M. (1964). Signs. Evanston: Northwestern University Press.

Merleau-Ponty, M. (1968). The Visible and The Invisible. (edited by Claude Lefort, translated by Alphonso Lingis). Evanston: Northwestern University, Studies in Phenomenology and Existential Philosophy.

Monk, C., Fifer, W. P., Myers, M. M., Sloan, R. P., Trien, L., \& Hurtado, A. (2000). Maternal stress responses and anxiety during pregnancy: Effects on fetal heart rate. Developmental Psychobiology, 36, 67-77.

Montirosso, R., Tronick, E., Morandi, F., Ciceri, F., \& Borgatti, R. (2013). Four-month-old infants long-term memory for a stressful social event. PloS One, 8(12), e82277.

Noë, A. (2004). Action in perception. MIT Press.

O'Regan, J. K., \& Noë, A. (2001). What it is like to see: A sensorimotor theory of perceptual experience. Synthese, 129, 79-103.

Patrick, J., Campbell, K., Carmichael, L., \& Probert, C. (1982). Influence of maternal heart rate and gross fetal body movements on the daily pattern of fetal heart rate near term. American Journal of Obstetrics and Gynecology., 144, 533-538.

Penfield, W. (1958). The Excitable Cortex in Conscious Man. The Sherrington lectures V. Liverpool: Liverpool University Press.

Piontelli, A. (1992). From fetus to child: An observational and psychoanalytic study. London: Routledge.

Piontelli, A. (2002). Twins - From fetus to child. London: Routledge.

Piontelli, A. (2015). Development of normal fetal movements, the last 15 weeks of gestation. Springer-Verlag. Putnam, H. (1991). Representation and reality. Cambridge, MA: The MIT Press.

Radman, Z. (Ed.). (2012). The background: Knowing without thinking. Palgrave Macmillan.

Ratcliffe, M. (2002). Heidegger's attunement and the neuropsychology of emotion. Phenomenology and the Cognitive Sciences, 1(3), 287-312.

Reid, T. (1764). An inquiry into the human mind: On the principles of common sense. Dublin: Alexander Ewing.

Reid, T. (1769). An inquiry into the human mind: On the principles of common sense. Third edition. London: Cadell \& Longman and Edinburgh: Kincaid \& Bell.

Reid, T. (1788). Essays on the active powers of man. Edinburgh: Printed for J. Bell (etc.). 
Reid, T. (1983). Inquiry and Essays. (edited by Ronald Beanblossom and Keith Lehrer). Indianapolis: Hackett. Rizzolatti, G., \& Craighero, L. (2004). The mirror-neuron system. Annual Review of Neuroscience., 27, 169-192. Rizzolatti, G., Fogassi, L., \& Gallese, V. (2001). Neurophysiological mechanisms underlying the understanding and imitation of action. Nature Reviews, Neuroscience., 2, 661-670.

Rosenthal, D. (2005). Consciousness and mind. Oxford: Oxford University Press.

Sacks, O. (1985). The man who mistook his wife for a hat. London: Duckworth.

Shimoko, S., \& Shams, L. (2001). Sensory modalities are not separate modalities: Plasticity and interactions. Current Opinion in Neurobiology, 11, 505-509.

Steffensen, S. V. \& Hodges, B. H. (2010). The ecology of values-realizing in dialogical and social systems. Paper given at the symposium Expression, Engagement, Embodiment: The Ecology of Situation Transcendence, University of Glasgow, February 2010.

Steinbock, A. J. (1999). Saturated intentionality. In D. Welton (Ed.), The Body: Classic and Contemporary Readings (pp. 178-199). London: Blackwell.

Stern, D. (1985). The interpersonal world of the infant: A view from psychoanalysis and developmental psychology. New York: Basic Books.

Stuart, S. A. J. (2007). Machine consciousness: Cognitive and Kinaesthetic imagination. Journal of Consciousness Studies., 14(7), 141-153.

Stuart, S. A. J. (2010a). Conscious machines: Memory, melody and imagination. Phenomenology and the Cognitive Sciences., 9(1), 37-51.

Stuart, S. A. J. (2010b). Enkinaesthesia, biosemiotics and the Ethiosphere. In Signifying Bodies: Biosemiosis, Interaction and Health. (Edited by Cowley, S. J., Major, J. C., Steffensen, S. V., Dinis, A.). (305-30). ISBN 978-972-697-191-7.

Stuart, S. A. J. (2011). Enkinaesthesia: the fundamental challenge for machine consciousness. International Journal of Machine Consciousness, 3(1), 145-162.

Stuart, S. A. J. (2012). Enkinaesthesia: The essential sensuous background for co-agency. In Z. Radman (Ed.), The Background: Knowing Without Thinking (pp. 167-86). London: Palgrave Macmillan.

Stuart, S. A. J. (2013). Privileging exploratory hands: Prehension, apprehension, comprehension. In Z. Radman (Ed.), The hand (pp. 329-347). MIT Press.

Stuart, S. A. J. (2015). Enkinaesthesia and Reid's natural kind of magic. In Thinking Thinking - Practicing Radical Reflection. (Edited by Schoeller, D. \& Saller V.). Schriftenreihe zur phänomenologischen Anthropologie und Psychopathologie, hg. v. T. Fuchs und T. Breyer, Freiburg. 92-111.

Stuart, S. A. J. \& Thibault, P. J. (2015). Enkinaesthetic polyphony as the underpinning for first-order Languaging. In: Emotion in Language: Theory - Research - Application. (Edited by Lüdtke U.). Consciousness and emotion book series, Amsterdam: John Benjamins. (113-34).

Thibault, P. J. (2011). First-order Languaging dynamics and second-order language: The distributed language view. Ecological Psychology, 23(3), 1-36.

Thompson, E. (2001). Empathy and consciousness. Journal of Consciousness Studies., 8(5-7), 1-32.

Thompson, R. A. (2014). Stress and child development. The Future of Children., 24(1), 41-59.

Trevarthen, C. (1993). The self born in intersubjectivity: The psychology of an infant communicating. In U. Neisser (Ed.), The Perceived Self: Ecological and Interpersonal Sources of Self- Knowledge (pp. 121173). New York: Cambridge University Press.

Trevarthen, C., \& Reddy, V. (2007). Consciousness in infants. In M. Velmans \& S. Schneider (Eds.), A Companion to Consciousness (pp. 41-57). Oxford: Blackwells.

Trevarthen, C., Aitken, K. J., Vandekerckhove, M., Delafieldt-Butt, J., \& Nagy, E. (2006). Collaborative regulations of vitality in early childhood: Stress in intimate relationships and post natal psychopathology. In D. Cichetti \& D. J. Cohen (Eds.), Developmental psychopathology. New York: John Wiley and Sons Limited.

Tronick, E. Z. (2007). The neurobehavioral and social-emotional development of infants and children. New York: Norton.

Tronick, E. Z., \& Beeghly, M. (2011). Infants meaning-making and the development of mental health problems. American Psychologist, 66(2), 107-119.

Tronick, E. Z., Als, H., Adamson, L., Wise, S., \& Brazelton, T. B. (1978). The infant's response to entrapment between contradictory messages in face-to-face interaction. Journal of the American Academy of Child \& Adolescent Psychiatry., 17, 1-13.

Twenge, J. M., Baumeister, R. F., Tice, D. M., \& Stucke, T. S. (2001). If you can't join them, beat them: Effects of social exclusion on aggressive behavior. Journal of Personality and Social Psychology., 81, 1058-1069.

Twenge, J. M., Baumeister, R. F., DeWall, C. N., Ciarocco, N. J., \& Bartels, J. M. (2007). Social exclusion decreases prosocial behavior. Journal of Personality and Social Psychology, 92(1), 56-66.

Uexküll, J V. (1982 / 1940). The theory of meaning. Semiotica 42(1), 25-87. 
Van Leeuwen, P., Geue, D., Thiel, M., Lange, S., Romano, M. C., Wessel, N., Kurths, J., \& Grönemeyer, D. H. (2009). Influence of paced maternal breathing on fetal-maternal heart rate coordination. Proceedings of the National Academy of Science, USA, 106(33), 13661-13666.

Vygotsky, L. S. (1967). Play and its role in the mental development of the child. Soviet Psychology., 5, 6-18.

Weinberg, M. K., \& Tronick, E. Z. (1996). Infant affective reactions to the resumption of maternal interaction after the still-face. Child Development, 67, 905-914.

Weinberg, M. K., Beeghly, M., Olson, K. L., \& Tronick, E. Z. (2008). A still-face paradigm for young children: 2 1/2 year-olds: Reactions to maternal unavailability during the still-face. Journal of Developmental Processes., 3(1), 4-21.

Willett, C. (2014). Interspecies ethics. Columbia University Press.

Wood, R., \& Stuart, S. A. J. (2009). Aplasic phantoms and the mirror neuron system: an enactive, developmental perspective. Phenomenology and the Cognitive Sciences, 8(4), 487-504.

Young, I. M. (1980). Throwing like a girl: A Phenomenology of feminine body comportment motility and spatiality. Human Studies., 3(2), 137-156. 